\title{
Optimization of Wind Farm Turbine Layout Including Decision Making Under Risk
}

\author{
Javier Serrano González, Manuel Burgos Payán, and Jesús M. Riquelme-Santos
}

\begin{abstract}
This paper presents a new contribution to optimal wind farm design, including the main risk management aspects. The objective of the algorithm is to optimize the expected profits of the wind farm by taking into account that the wind data used to design the wind farm involves some degree of uncertainty that affects the final return of the project. Net present value (NPV) will be used as a figure of the profitability in the proposed method. The maximization of the NPV means the maximization of the cumulative net cash flows (by maximizing the generation of net energy) and minimization of the investment. Both terms mainly depend on the number and type of wind turbines, tower height, and geographical position, among other factors. Therefore, the tool developed in this paper is intended to determine the wind farm configuration most suitable in the presence of risk due to uncertainty in the wind data.
\end{abstract}

Index Terms-Expected value, genetic algorithm, risk management, utility theory.

\section{INTRODUCTION}

$\mathbf{T}$ HE USE OF wind energy to generate electricity is becoming more and more important in most countries. Current interest in renewable energy resources, such as wind power, is mainly due to double support. On the one hand, it is driven by the economic and political aspects, such as the upward trend in fossil fuel prices and insecurity of supply. On the other, there are social and environmental aspects, resulting from the ever-increasing social awareness about the harmful impacts of the emission of greenhouse gases responsible for global climate change.

Wind power installed worldwide by the end of 2010 will amount to a total of $196.63 \mathrm{GW}$, of which $85.98 \mathrm{GW}$ corresponds to Europe, and of these, $20.68 \mathrm{GW}$, to Spain [1]. The growth rate of total installed capacity in the world was $19 \%$ in 2010. This value has remained relatively constant during the last few decades, and nothing seems to indicate that much will change in the coming years.

A wind farm is made by a cluster of wind turbines (WTs), more or less packed. This configuration offers some economic

Manuscript received September 15, 2010; revised May 12, 2011; accepted May 25, 2011. This work was supported in part by the Ministry of Science and Technology, Spain, under Research Projects ENE207-66072/ALT, ENE200768032-C04-02, and ENE2011-27984, and in part by the Government of Andalusia, under Projects P06-TEP-01882 and TEP-5170.

The authors are with the Department of Electrical Engineering, School of Engineering, University of Seville, Seville 41092, Spain (e-mail: javierserrano@us.es; mburgos@us.es; jsantos@us.es).

Color versions of one or more of the figures in this paper are available online at http://ieeexplore.ieee.org.

Digital Object Identifier 10.1109/JSYST.2011.2163007 advantages related to the investment, plant operation, and maintenance costs. However, the WT compactness degree is limited by spacing constraints due to the wake effects (the screening effect produced by the rotor of a turbine on those located behind it, downstream). As a consequence, the layout of specific individual WT positions determines the overall efficiency of extraction of wind energy in a wind farm.

The design of a wind plant aimed at generating electricity and its proper operation, over the facility life span, is a complex and multidisciplinary task that involves many different areas of expertise, from engineering to other sciences. It is not only a complex enterprise from a technological standpoint but also a degree of uncertainty, in terms of return or profitability, that is higher than desirable. There are many factors that influence the uncertainty in the returns on investment. Among these, the main are as follows.

1) Future prices and costs: The future prices of goods, such as the price of the energy or discount rate, are obviously unknown. But, in order to estimate the present return from selling the electricity produced, it is necessary to know the selling price of the energy and discount rate, throughout the whole span life of the wind farm (typically 20 years). This could also include the costs of various factors that influence the normal development of the project during construction (such as civil work or implementation delays), operation (turbine unavailability, losses in the distribution network, wake effect losses, or maintenance cost), and in the final phase of decommissioning or possible future regulatory changes that could affect the economic or financial scenario.

2) Wind: The sale of generated electric energy is the source of income of the wind farm. Therefore, the random nature of wind (speed distribution and directions) introduces some degree of uncertainty in annual energy production. In this sense, it is worth noting that the optimum positioning of each of the turbines within a wind farm is one of the major factors that influence the profitability of the installation. This is due to the turbine wake effect. Wake effect losses are the result of interaction of two main factors: the wind (wind rose and speed, not controllable) and layout of the turbines in the wind farm (controllable at the project stage).

In this paper, the problem of the optimal design of wind farms (selection of the turbines location, turbine type, and hub height), taking into account the uncertainty in the statistical 


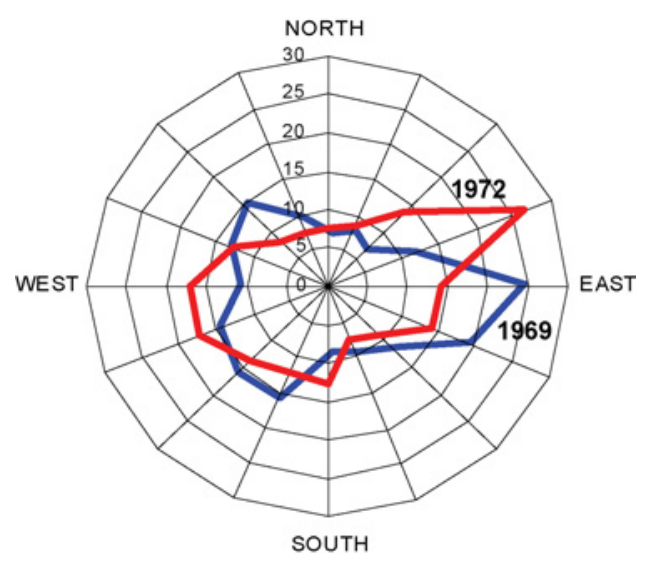

Fig. 1. Example of annual variation in the compass rose. Wind rose from List/Sylt (Germany) for the years 1969 and 1972 [4].

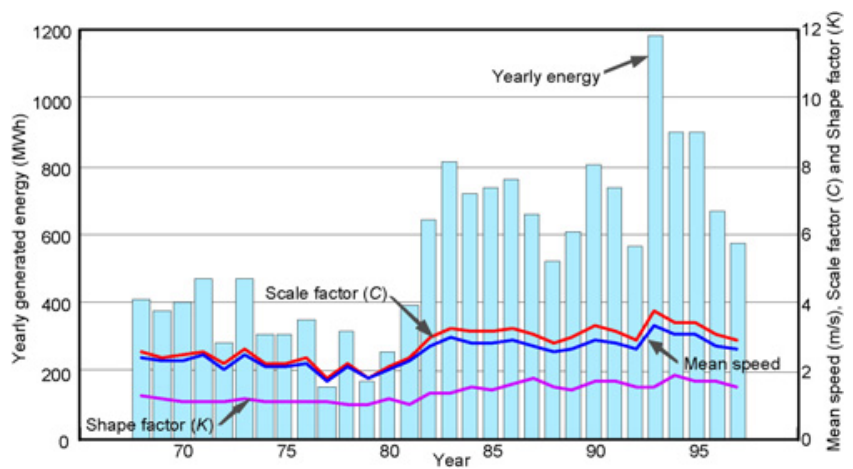

Fig. 2. Change in Weibull parameters, mean wind speed, and estimated yearly generation of energy in Hong Kong since 1968 until 1997 [5].

characterization of the wind, is analyzed. The uncertainty from the wind information, in both wind direction and intensity (speed), becomes an uncertainty in the estimation of the yearly generated energy. It is, therefore, the factor that most directly affects the profitability of the wind farm. But, fortunately, at the same time, it is the most controllable factor in the design stage (optimizing the turbine layout). The objective is to determine the configuration of the wind farm, so that the uncertainty of the profitability is set to a level of risk acceptable for investors. Moreover, the study should allow the investor to know the maximum and minimum levels of profitability of the project, which is an essential piece of information in investor decision making when deciding whether to undertake or reject the project [2], [3].

As an example of uncertainty of wind data, Fig. 1 shows changes in the wind rose at List/Sylt (Germany), measured in 1969 and 1972 [4]. Fig. 2 shows the variations in Weibull distribution parameters (scale, $C$, and shape, $K$ ), mean wind speed, and estimated annual energy produced along 30 years in Hong Kong (adapted from [5]).

To date, there are several papers that use a mathematical model to optimize the solution of the location problem (positioning or micrositing) of WTs in a wind farm. In [6]-[9], the authors proposed a rather simple wind farm cost model because they were mainly interested in demonstrating the effectiveness of the optimization algorithm. The four papers use the same wake decay, simplified cost models, and very similar objective functions, and they analyze the same cases. They only differ in the optimization technique. While [6] and [8] used a genetic algorithm (GA), [7] used a greedy algorithm and [9] used a Monte Carlo simulation.

A more realistic wind farm cost model is developed in [10][12] using a GA as the optimization algorithm. In relation to the use of decision methods applied to the planning of wind farms, the most significant work was done by [13], where the objective was to determine the most appropriate generation capacity under uncertainty.

This paper introduces a new approach to the problem of optimal positioning of turbines in a wind farm, including decision making under risk. As mentioned above, the economic performance of a wind farm has a high degree of uncertainty. Therefore, in this paper, a probabilistic optimization methodology has been developed by taking into account a set of possible scenarios and their probability of occurrence. This probabilistic approach allows obtaining solutions with a behavior under risk better than the performance of configurations obtained by the deterministic approaches developed to date.

After this introduction, the paper is organized as follows. Section II describes the problem approach and proposed methodology. Section III presents the economic model of the wind farm. Test cases and conclusions are provided in Sections IV and V, respectively.

\section{Methodology}

The proposed tool combines an evolutionary algorithm, as the optimization technique, with a decision method under risk (Fig. 3). An initial population with a set of possible solutions (individuals) is randomly generated by the evolutionary algorithm. This population evolves, generation after generation, toward the optimum by means of the crossover and mutation operators. The fitness of each individual is evaluated by the decision method that assesses the economical suitability [based on net present value (NPV)] of each of the individuals composing the population (alternatives) for the set of scenarios (states of nature).

\section{A. Optimization Algorithm}

The complexity of the problem of optimal positioning of the WTs in a wind farm arises not only from a technical point of view, due to strong links between its variables, but also from a purely mathematical point of view. The problem consists of both discrete and continuous variables, being, therefore, an integer-mixed type problem. The problem exhibits manifold optimal solutions (convexity) and cannot be completely described in an analytical form; some variables have a range of non-allowed values (solutions space not simply connected) and others are integers. This fact makes the problem non-derivable, preventing the use of classical analytical optimization techniques.

GAs have been used successfully in previous work to optimize the problem of micro-positioning of the turbines of a wind farm and demonstrated their suitability to the complexity of this problem [6], [8], [10]-[12]. GA are robust optimum 


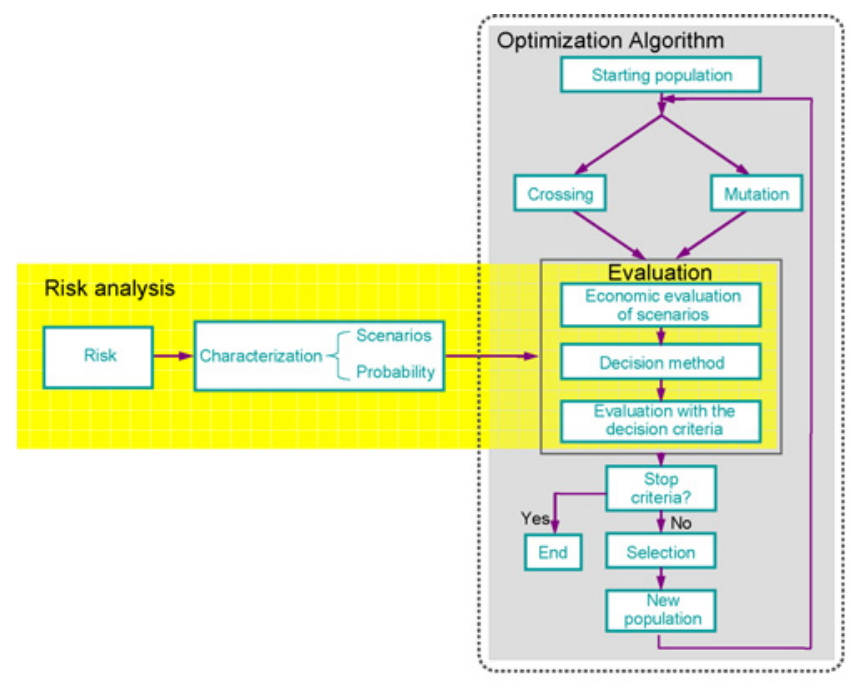

Fig. 3. Optimization algorithm incorporating uncertainty (risk) scenarios.

search techniques that find the minimum or maximum of a function based on principles inspired from the natural genetic and evolution mechanisms observed in the nature [14]-[16]. The type and height of the WTs are discrete variables that are not easily managed by traditional numerical algorithms due to the nondifferentiable nature of the problem. Therefore, integer codification has been used in the algorithm implementation, which has been also applied to the locations of the WTs.

The integer codification used represents every possible solution of the problem by means of a matrix, where the columns refer to the turbines of an individual and every row codifies the characteristics for each turbine: position of the wind generator in Cartesian coordinates $\left(X_{i}, Y_{i}\right)$, type of wind generator $\left(T_{i}\right)$, and tower height $\left(H_{i}\right)$. The type of turbine is codified with a number, which will be the index in the generator database that uses the algorithm as an input. The aforementioned database contains all the necessary information of the wind generators that could be installed in the wind farm (i.e., maximum and minimum height of the towers, turbine and tower costs, foundation cost, and power-wind speed curve). Therefore, these matrices have a variable number of columns, depending on the number of generators required by the codified individual solution [17]-[19].

GA mainly makes use of two kinds of operators to generate new individuals (potential solutions): crossover and mutation. The crossover operator is applied on two selected individuals, called parents, to generate new individuals, called sons, with a mix of chromosomes (characteristics) from the parents. The selection method used is known as roulette wheel, where the individuals with highest fitness (objective function) are more likely to be selected. Five special types of crossover operators have been developed to improve the algorithm performance [17]-[19]. The mutation operator is applied on one individual to generate another by randomly changing one or more chromosomes. When the population is confined in a local maximum, this operator leads to the creation of individuals out of this zone of local attraction. This way the algorithm can evolve toward the global maximum. The optimization algorithm manages several kinds of constraints that makes
TABLE I

RESULTS MATRIX: NPV FOR EACH INDIVUAL AND SCENARIO

\begin{tabular}{|l|c|c|c|c|c|c|}
\hline Scenario & $S_{1}$ & $\ldots$ & $S_{j}$ & $\ldots$ & $S_{m}$ & $\mathrm{EV}(\mathrm{NPV})$ \\
\hline $\begin{array}{l}\text { Scenario } \\
\text { probability }\end{array}$ & $p_{S 1}\left(E_{1}\right)$ & $\ldots$ & $p_{S j}\left(E_{j}\right)$ & $\ldots$ & $p_{S m}\left(E_{m}\right)$ & $\mathrm{EV}_{1}=\sum_{j=1}^{m} \mathrm{NPV}_{1 j} p_{j}$ \\
\hline Individual 1st & $\mathrm{NPV}_{11}$ & & $\mathrm{NPV}_{1 j}$ & & $\mathrm{NPV}_{1 m}$ & $\mathrm{EV}_{2}=\sum_{j=1}^{m} \mathrm{NPV}_{2 j} p_{j}$ \\
\hline$\ldots$ & $\ldots$ & $\ldots$ & $\ldots$ & $\ldots$ & $\ldots$ & $\ldots$ \\
\hline Individual $i$ th & $\mathrm{NPV}_{i 1}$ & $\ldots$ & $\mathrm{NPV}_{i j}$ & $\ldots$ & $\mathrm{NPV}_{i m}$ & $\mathrm{EV}_{i}=\sum_{j=1}^{m} \mathrm{NPV}_{i j} p_{j}$ \\
\hline$\ldots$ & $\ldots$ & $\ldots$ & $\ldots$ & $\ldots$ & $\ldots$ & $\ldots$ \\
\hline Individual $n$th & $\mathrm{NPV}_{n 1}$ & $\ldots$ & $\mathrm{NPV}_{n j}$ & $\ldots$ & $\mathrm{NPV}_{n m}$ & $\mathrm{EV}_{n}=\sum_{j=1}^{m} \mathrm{NPV}_{n j} p_{j}$ \\
\hline
\end{tabular}

the process of designing a wind farm more flexible, such as follows.

1) Setting up forbidden areas where, for different reasons, it is not possible to place a turbine. When an individual shows a wind generator in a forbidden area, the genes corresponding to the position of this aerogenerator are mutated till they become located in an allowed area.

2) Turbines on the same position or outside the terrain. Usually, after the operation of crossover or mutation, non-feasible solutions can be created. In this case, a regenerative algorithm goes through the individuals, removing the turbines that are wrongly placed.

3) Limitation of the maximum investment to be done if the investor has a limited available capital to start the project. This constraint will be taken into account by penalizing the individual in case of overinvestment.

4) Limitation in the maximum number of generators. This restriction is controlled by limiting the number of the individuals throughout the generation of the initial population and crossing operation.

\section{B. Methods of Decision Making}

When addressing the wind farm optimization problem within the framework of a deterministic approach, once the input variables values are set (the deterministic scenario), an optimization algorithm, based on GA techniques, determines the optimal configuration of the wind farm Fig. 4(a). But, when addressing the problem with a risk approach, the uncertainty in the input variables must be considered Fig. 4(b). Now, the input variables are characterized by a set of scenarios $\left(S_{1}, S_{2}, \ldots, S_{N}\right)$ and its probability of occurrence $\left(p_{1}, p_{2}, \ldots, p_{N}\right)$. In this case, Table I shows the corresponding matrix results. As can be seen, the $\mathrm{NPV}_{i j}$ element of this matrix shows the NPV related to the $i$ th potential wind farm configuration (individual $i$ th), considering the $j$ th scenario $\left(S_{j}\right)$.

In this paper, two different objective functions were used depending on the decision criterion adopted: maximum expected value (MEV) or maximum expected utility (MEU), based on the utility theory (UT).

With the MEV approach, the objective is to find the wind farm configuration with MEV of NPV. To reach that goal, the expected value (EV) of NPV for each individual must be 


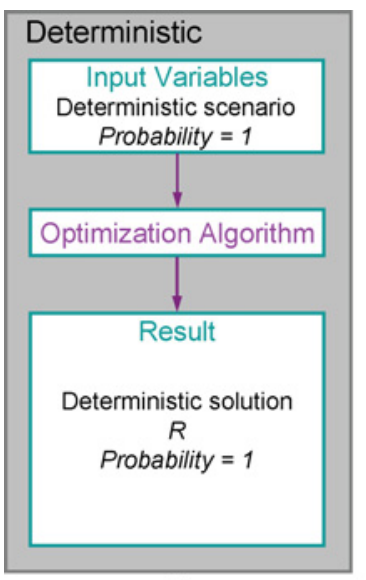

(a)

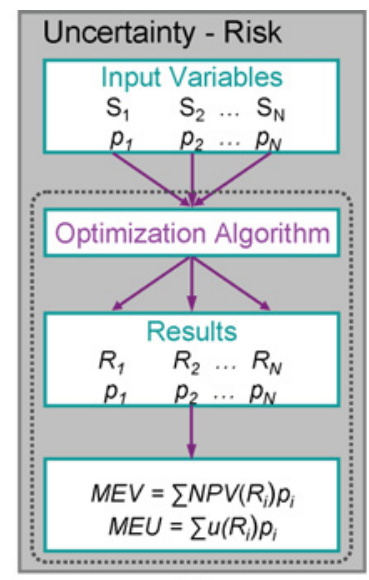

(b)
Fig. 4. Optimization algorithm. (a) Deterministic approach. (b) Incorporating uncertainty (risk) scenarios.

calculated as [20]

$$
\mathrm{EV}_{i}=\sum_{j=1}^{m} \mathrm{NPV}_{i j} p_{j}
$$

The MEU criterion is based on the UT. The UT models the behavior of the decision maker by means of a function (the utility function) expressing the preference of the decision maker for each one of the alternatives. The utility function used in this paper is an exponential type [2] defined by

$$
u(\mathrm{NPV}(x))= \begin{cases}\frac{1-e^{-\left(\mathrm{NPV}(x)-\mathrm{NPV}_{\text {min }}\right) / \rho}}{1-e^{-\left(\mathrm{NPV}_{\text {max }}-\mathrm{NPV}_{\text {min }}\right) / \rho},}, & \text { if } \quad \rho \neq \infty \\ \frac{\mathrm{NPV}(x)-\mathrm{NPV}_{\text {min }}}{\mathrm{NPV}_{\text {max }}-\mathrm{NPV}_{\text {min }}}, & \text { if } \quad \rho \rightarrow \infty\end{cases}
$$

where $u$ is the utility value corresponding to $\operatorname{NPV}(x), x$ is the configuration of the wind farm, and $\rho$ is the parameter of risk tolerance. The utility function reaches the maximum value, equal to one, for $\mathrm{NPV}_{\max }$, and the minimum value, equal to zero, for $\mathrm{NPV}_{\text {min }}$. In this paper, $\mathrm{NPV}_{\text {min }}$ has been taken as the minimum value of NPV that the decision maker would be willing to accept to undertake the project, and $\mathrm{NPV}_{\text {max }}$ is the maximum value of $\mathrm{NPV}_{i j}$ corresponding to the matrix of results throughout the evolution of the GA.

Fig. 5 shows, as an example, the family of utility curves depending on the risk tolerance parameter. The risk tolerance parameter, $\rho$, allows modeling the attitude of the decision maker. If $\rho>0$, the decision maker is risk averse because, as the NPV increases, the slope of the utility curve decreases. If $\rho<0$, the decision maker is risk seeking (the decision maker increasingly appreciates NPV increases). In both cases, the higher the risk tolerance, the higher the risk preference of the decision maker. The extreme case is reached when the value of risk tolerance is infinite $(\rho \rightarrow \pm \infty)$, representing a neutral decision maker attitude toward risk because the utility curve is a straight line. Therefore, the decision maker uniformly values each increment of NPV. Finally, in this approach, the objective

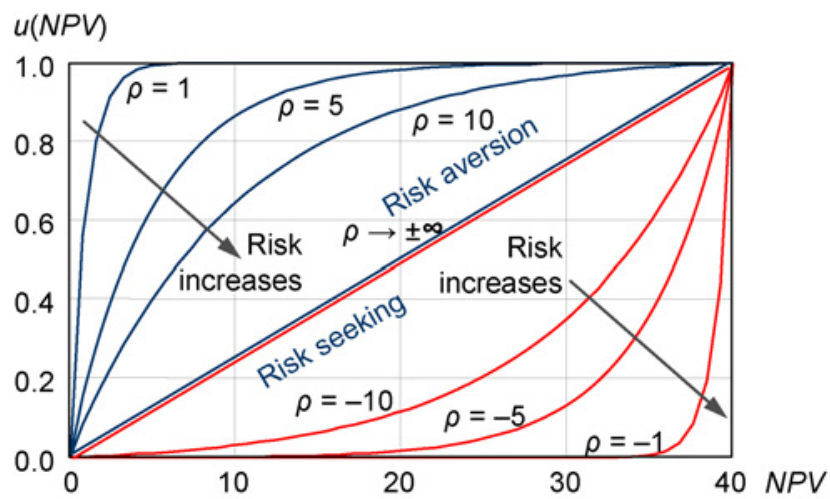

Fig. 5. Decision-maker attitude depending on the risk tolerance parameter.

will be achieved as the MEU is calculated by

$$
\mathrm{EU}_{i}=\sum_{j=1}^{m} u\left(\mathrm{NPV}_{i j}\right) \cdot p_{j}
$$

Both criteria (MEV and MEU) is necessary to calculate the NPV for each scenario and potential solution (individual) taking into account the economic model of the wind farm detailed in the third section.

\section{WIND FARM ECONOMIC MODEL}

A wind farm with a certain turbine configuration (turbine rated capacity, type, height, and location), $x$, requires an initial capital investment to build and put the facility into production, $I_{\mathrm{WF}}(x)$. This initial investment is necessary mainly to afford the WT acquisition costs, as well as the civil and electrical infrastructure costs. The wind farm, once in operation, delivers a stream of both financial benefit (profits from the generated electric energy selling), $N_{\mathrm{ESk}}(x)$, and ordinary operation and maintenance costs, $C_{\mathrm{O \& Mk}}(x)$, year after year, over the life span of the project, $L T$. A final present cost for the installation decommissioning, $C_{D}(x)$, and a present residual value, $V_{R}(x)$, after the production period, must also be considered. This way, the NPV of the wind farm, $\operatorname{NPV}(x)$, taking into account the equivalent discount rate, $r$, can be written as

$$
\mathrm{NPV}(x)=-I_{\mathrm{WF}}(x)-C_{D}(x)+V_{R}(x)+\sum_{k=1}^{\mathrm{LT}} \frac{N_{k}(x)}{(1+r)^{k}}
$$

where the net cash flow, $N_{k}$, represents the net incomes produced by the wind farm during the $k$ th year. This term is only the difference between the income resulting from the energy sale and operation and maintenance costs, $N_{k}(x)=$ $N_{\mathrm{ESk}}(x)-C_{\mathrm{O} \& \mathrm{Mk}}(x)$. Therefore, the maximization of the NPV means a balance between the minimization of the investment and maximization of the net cash flows (to maximize the net generation of energy). Both terms depend on the number and type of wind generators, tower height, and geographical position, among others. Table II shows a typical cost breakdown of a wind farm, adapted from [21]. As can be seen, most of the initial investment is for the purchase of WTs, while the remaining investment is aimed at the costs of electrical 
TABLE II

TYPICAL INITIAL COST STRUCTURE OF A WIND FARM

\begin{tabular}{|c|c|c|}
\hline \multicolumn{2}{|l|}{ Item } & $\%$ \\
\hline \multicolumn{2}{|l|}{ WTs } & $65-75$ \\
\hline \multicolumn{2}{|l|}{ Substation and electrical infrastructure } & $10-15$ \\
\hline Inner electrical distribution installation & $6-9 \%$ & \\
\hline Substation and evacuation line connection & $4-6 \%$ & \\
\hline \multicolumn{2}{|l|}{ Civil work } & $5-10$ \\
\hline \multicolumn{2}{|l|}{ Component installation } & $0-5$ \\
\hline \multicolumn{2}{|l|}{ Other } & 5 \\
\hline Overall WT cost $(€ / \mathrm{kW})$ & \multicolumn{2}{|c|}{$800-1200$} \\
\hline
\end{tabular}

and civil infrastructure. The main problem to be solved is the positioning and selection of the turbines (type and height of the tower), and this is the problem that has the greatest influence on the wind farm profitability. The costs of civil works are relatively simple to calculate, however, the design of the electrical installation is a complex problem and its exact calculation would involve a high consumption of CPU time. This reason, in addition to the relatively low economic weight of the electrical installations, allows an approximation of the electrical costs to be considered equal to the civil work cost.

To obtain a wind farm NPV as realistic as possible, the evolution of the prices of the sold energy, as well as the increment of the operation and maintenances cost, must be considered. Assuming that $E_{k}(x)$ is the annual net amount of electric energy produced and sold at year $k, p_{\mathrm{kWh}}$ is the price of the kilowatt-hour of sold energy, $\Delta p_{\mathrm{kWh}}$ is its annual increment, and $\Delta C_{\mathrm{O} \& \mathrm{M}}$ is the annual increment of the cost of operation and maintenance, then the NPV of the cash flow along the wind farm life span yields

$$
\begin{aligned}
\mathrm{NPV}(x)= & -I_{\mathrm{WF}}(x)-C_{D}(x)+V_{R}(x) \\
& +\sum_{k=1}^{\mathrm{LT}} \frac{E_{k}(x) P_{\mathrm{kWh}}\left(1+\Delta p_{\mathrm{kWh}}\right)^{k+1}}{(1+r)^{k}} \\
& -\sum_{k=1}^{\mathrm{LT}} \frac{C_{\mathrm{O \& MK}}(x)\left(1+\Delta C_{\mathrm{O} \& \mathrm{M}}\right)^{k+1}}{(1+r)^{k}} .
\end{aligned}
$$

To properly evaluate the potential energy supplied by the wind farm during a year, the wake speed decay effect must be considered due to the perturbation of the wind speed profile as a result of the operation of the turbines located upstream [22]-[24]. The actual net energy produced and sold by a set of turbines in a wind farm is lower that of the sum of the energies of the turbines if they were isolated. This is due to two kinds of losses: the wake effect previously mentioned and the unavailability of the WTs (due to maintenance, repair or technical restrictions).

\section{A. Wind Behavior Model}

The statistical behavior of the wind at a given altitude will be approximated by the Weibull distribution function [25] that describes frequency, $p(v)$, for a given wind speed, $v$, as a function of the shape parameter, $K$, and the scale parameter, $C$, using the formula

$$
p(v)=\frac{K}{C}\left(\frac{v}{C}\right)^{K-1} \exp \left(-\left(\frac{v}{C}\right)^{K}\right) .
$$

Wind speed depends on altitude due to the existing friction of the air with the ground surface. Given the wind speed, $v\left(z_{r}\right)$, for a reference height, $z_{r}$, the corresponding wind speed at a different height, $z$, can be calculated using an exponential function

$$
v(z)=v\left(z_{r}\right) \frac{\ln \left(z / z_{0}\right)}{\ln \left(z_{r} / z_{0}\right)}
$$

where $z_{0}$ is the length of roughness for the terrain [26].

The collection of wind energy done by a turbine reduces the speed of the wind through it, causing a reduction in the kinetic energy available for the turbines located downstream in the direction of the incident wind. The resulting wind speed at a distance, $d$, downstream of the turbine that creates the wake is calculated by [23]

$$
\frac{U(d)}{U_{0}}=\frac{1}{2}+\frac{1}{2} \sqrt{1-2 C_{T}\left(\frac{D_{0}}{D(d)}\right)^{2}}
$$

where $U_{0}$ is the speed of the wind in free flow, $D_{0}$ is the diameter of the rotor, $D(d)$ the wake diameter, and $C_{T}$ the dimensionless thrust coefficient.

Finally, the calculation of the electric energy generated in a year, can be obtained by combining the long-term distribution of the wind speed considering the different directions of the wind rose, and the curve of specific power of the turbine, for each type of generator considered in the wind farm as follows:

$$
E_{\mathrm{WF}}=T \sum_{j=1}^{N_{t}} \int_{v_{c i j}}^{v_{c o j}} k_{A v j} P_{G e n j}(v) p_{j}(v) d v
$$

where $T$ is the number of hours per year $(T=8760 \mathrm{~h}), N_{t}$ is the number of turbines, $v_{c i j}$ is the cut-in speed (speed at which the turbine starts generation) for turbine $j$ and $v_{c o j}$ is the cut-out speed (the final generation speed) for turbine $j$, $P_{G e n j}(v)$ is the power-velocity curve for generator $j$, and $k_{A V j}$ is the availability factor for turbine $j$.

\section{B. Civil Infrastructure Cost}

Civil infrastructure costs are made up mostly of foundation costs and costs derived from the execution of auxiliary roads to access the wind generators. The first entry depends on the position of the wind generators and is calculated according to typical values, taking into account an increase in the foundation costs for cases where the wind generators are located in areas with a reduced bearing capacity. The cost of building auxiliary roads is made up of the activities of clearing, filling, and compaction of roads, which are directly proportional to its total length. The Prim algorithm for calculation of minimum spanning tree [27] has been used to calculate the configuration and length of the auxiliary roads.

\section{TEST CASES}

A set of cases has been solved to show the suitability of the proposed algorithm. The decision methods, MEV and MEU, have been combined with the optimization algorithm to select the most appropriate design for each situation and level of risk that the decision maker is willing to assume. In both cases, 


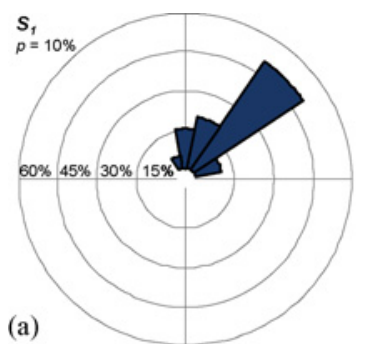

(a)

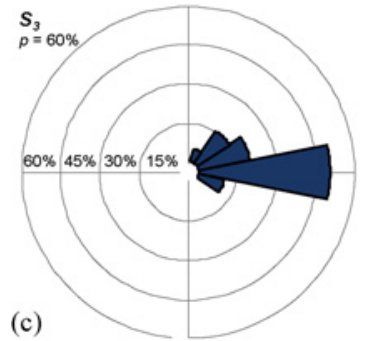

(b)
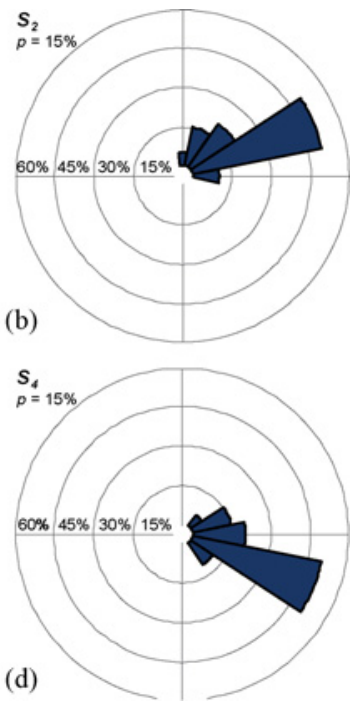

Fig. 6. Wind rose and probability for each considered scenario. (a) $S_{1}$. (b) $S_{2}$. (c) $S_{3}$. (d) $S_{4}$.

TABLE III

MAIN FEATURES OF WTS

\begin{tabular}{|l|c|c|c|}
\hline & WTA & WTB & WTC \\
\hline Rated capacity $(\mathrm{MW})$ & 2000 & 2000 & 1670 \\
\hline Minimum height $(\mathrm{m})$ & 60 & 60 & 60 \\
\hline Maximum height $(\mathrm{m})$ & 100 & 100 & 80 \\
\hline Cost $(\mathrm{M} €)$ & 2.10 & 2.00 & 1.67 \\
\hline Tower cost $(\mathrm{k} € / \mathrm{m})$ & 1.5 & 1.5 & 1.5 \\
\hline Foundation cost $(\mathrm{k} €)$ & 80 & 80 & 80 \\
\hline
\end{tabular}

uncertainty in the data for the characterization of wind has been considered: the wind direction in Case 1 and wind speed and direction in Case 2.

\section{A. Case 1: Wind Direction Uncertainty}

Fig. 6 shows the four scenarios considered for the possible wind directions. Each scenario has a probability of occurrence. In addition, each scenario consists of the probability that the wind comes from each of the directions that make up the wind rose. Over the whole terrain, the wind speed is defined by the same scale factor $(C=6.5)$ and shape $(K=2)$ for the Weibull distribution. The study has been carried out on a square terrain of dimensions $3 \times 3 \mathrm{~km}$ discretized in $10 \times 10$ cells as in Fig. 7. The parcel is crossed by a road from east to west in the northernmost area. Cells crossed by the main road and near the northwest corner of the land are forbidden areas where WT placement is not allowed. In the northeast, there is an area where the bearing capacity of soil is reduced so that the foundation costs will be higher.

Table III shows the catalog of turbines from which the algorithm can select. Fig. 8 shows the power-speed curves of the WTs considered. Table IV shows the main technical and economic input data to the algorithm.

For each scenario, the deterministic optimal solution (DOS) has been calculated. These solutions are shown in Fig. 9. Table V shows for each of the DOS, the EV and NPV (M€) that would be obtained for other scenarios. As can be seen,

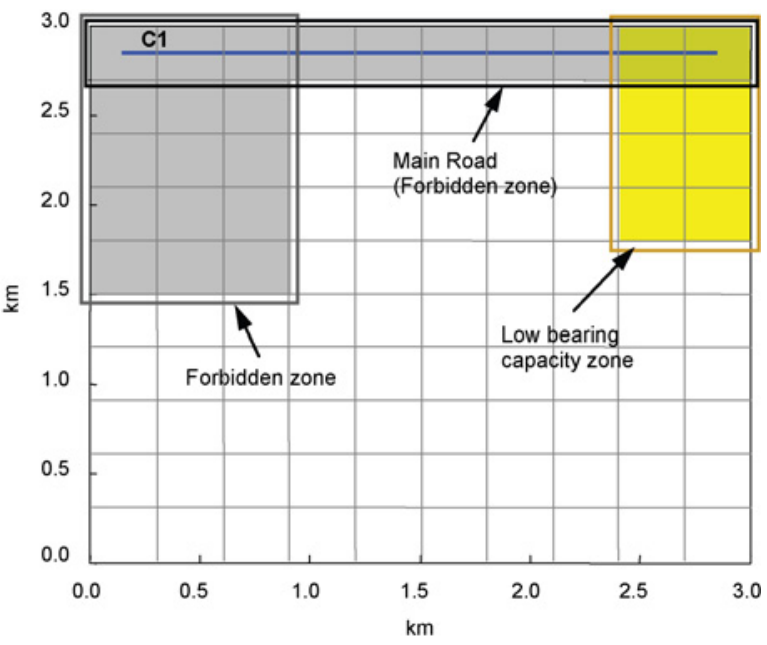

Fig. 7. Main terrain features for Case 1.

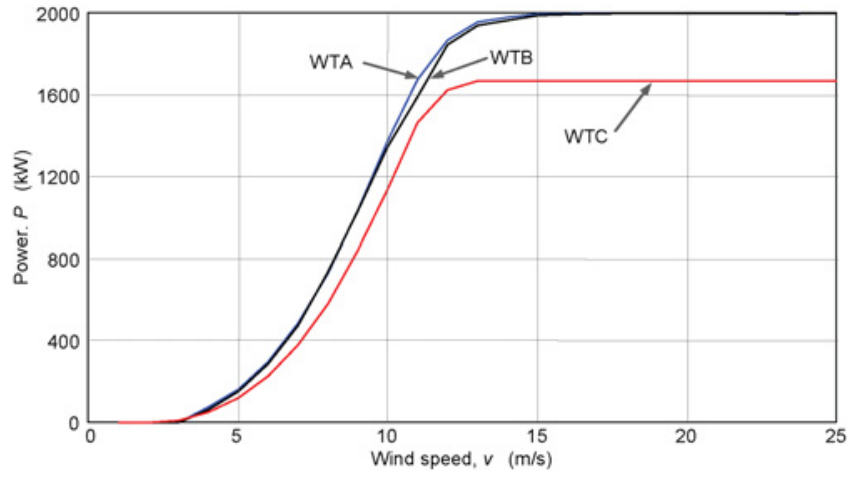

Fig. 8. Power-speed curves of considered WTs.

TABLE IV

MAIN TECHNICAL AND ECONOMICAL INPUT DATA

\begin{tabular}{|l|c|}
\hline Life span (years) & 20 \\
\hline Interest rate $(\%)$ & 6 \\
\hline Price of energy (€/kWh) & 0.07 \\
\hline Maximum no. of turbines & 8 \\
\hline Auxiliary roads cost (€/m) & 100 \\
\hline Overcost in area of low bearing capacity (\%) & 25 \\
\hline Roughness length $(\mathrm{m})$ & 0.0055 \\
\hline Availability factor $(\%)$ & 95 \\
\hline Present cost of decommission $(\%)$ & 3 \\
\hline Present residual value $(\%)$ & 3 \\
\hline Minimum NPV to undertake the project $(\mathrm{M} €)$ & 1 \\
\hline
\end{tabular}

for each of the scenarios, the maximum values are achieved for the deterministic solution for that scenario.

Fig. 10 shows the optimal solution reached by the algorithm taking into account the MEV criterion. The selected WTs are type B (WTB) with a height tower of $100 \mathrm{~m}$. In this case, the algorithm reaches the optimal solution in 254 generations using a running time of $1170 \mathrm{~s}$, on a PC Intel Pentium Dual Core $2 \mathrm{GHz}$. The second column of Table VI shows the main economical results obtained by the algorithm for Case 1 .

By using the MEU criterion, the aim is to maximize the expected utility (EU) using the exponential utility function detailed in (2). The case has been performed several times 
TABLE V

RESULTS OF CASE 1: NPV (M€) DOS FOR EACH SCENARIO

\begin{tabular}{|c|c|c|c|c|c|}
\hline & Scenario 1 & Scenario 2 & Scenario 3 & Scenario 4 & EV \\
\hline DOS $\left(S_{1}\right)$ & 21.02 & 20.78 & 19.69 & 20.41 & 20.09 \\
\hline DOS $\left(S_{2}\right)$ & 20.76 & 21.21 & 20.40 & 16.30 & 19.94 \\
\hline DOS $\left(S_{3}\right)$ & 20.20 & 20.77 & 21.05 & 21.05 & 20.93 \\
\hline DOS $\left(S_{4}\right)$ & 20.20 & 20.77 & 21.05 & 21.05 & 20.93 \\
\hline
\end{tabular}

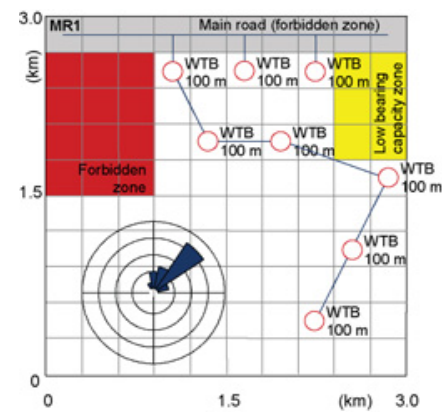

(a)

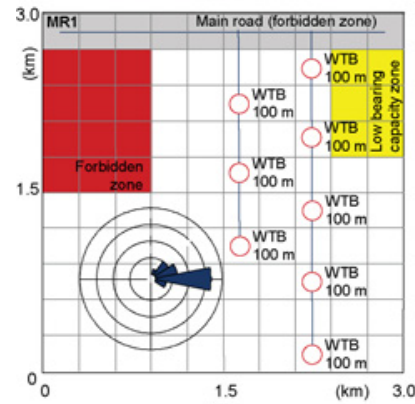

(c)

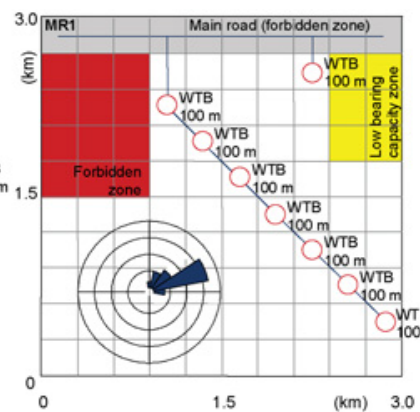

(b)

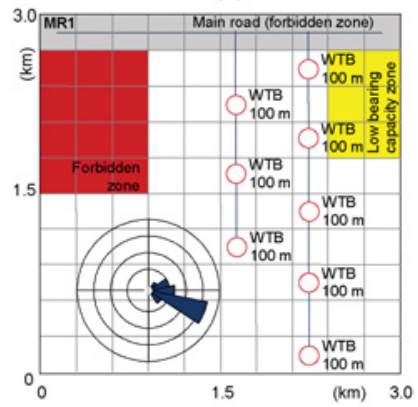

(d)
Fig. 9. DOS obtained for each scenario. (a) Scenario 1. (b) Scenario 2. (c) Scenario 3. (d) Scenario 4 .

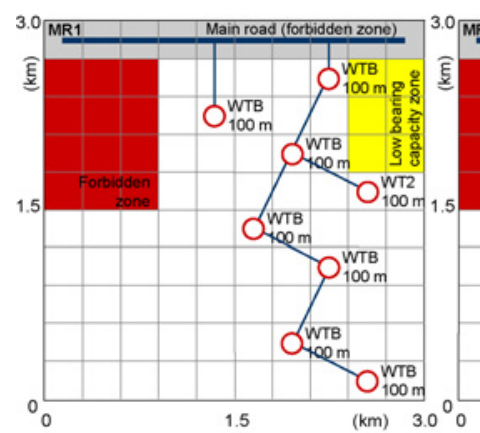

(a)

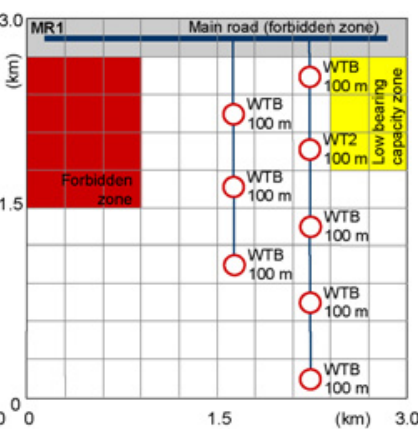

(b)
Fig. 10. Optimal layout obtained by the MEV criterion for (a) Case 1 and (b) Case 2.

by varying the decision-maker attitude (by varying the value of risk tolerance, $\rho$ ). Fig. 11 shows the optimal configuration depending on the risk tolerance parameter.

Table VII shows the results obtained by the algorithm for Case 1 using the MEU criterion. Each row shows the NPV (M€), for each scenario and its EV, for each optimal configuration depending on the parameter of risk tolerance, $\rho$ (the risk preference increases moving down in the table). With aversive or neutral attitudes to risk $(\rho \geq 0)$, the optimal solution is the same as that obtained by the MEV criterion

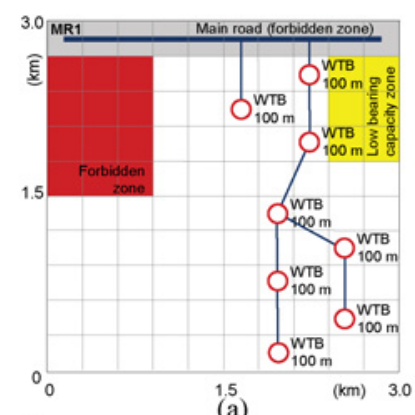

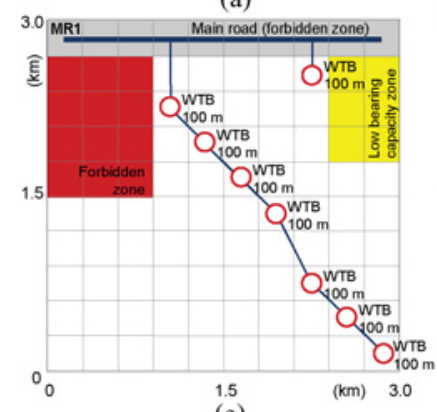

(c)

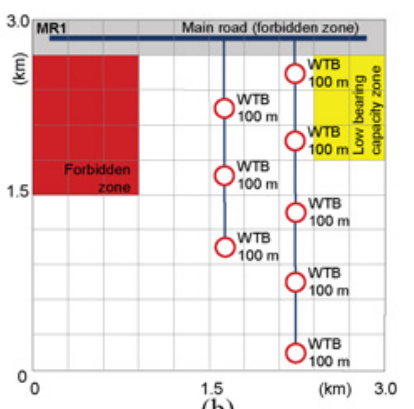

(b)

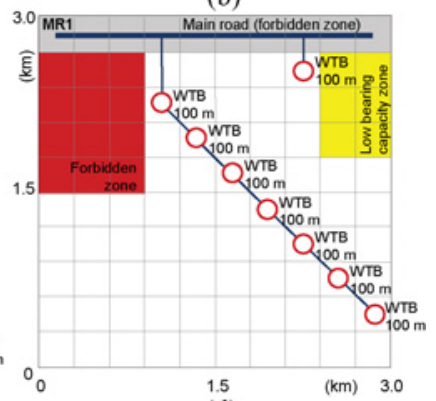

(d)
Fig. 11. Optimal layout obtained for Case 1 by the MEU by varying the risk tolerance of the decision maker. (a) $\rho=-0.01$. (b) $\rho=-0.008$. (c) $\rho=-0.005$. (d) $\rho=-0.002$.

TABLE VI

MAIN ECONOMICAL RESULTS OBTAINED WITH MEV CRITERION

\begin{tabular}{|l|c|c|}
\hline & Case 1 & Case 2 \\
\hline EV of NPV $(\mathrm{M} €)$ & 20.96 & 19.06 \\
\hline Investment $(\mathrm{M})$ & 19.91 & 19.79 \\
\hline Turbines cost $(\mathrm{M} €)$ & 17.20 & 17.20 \\
\hline Civil infrastructure cost $(\mathrm{M} €)$ & 1.35 & 1.30 \\
\hline Electrical infrastructure cost $(\mathrm{M} €)$ & 1.35 & 1.30 \\
\hline Average power EV $(\mathrm{kW})$ & 4042 & 3842 \\
\hline
\end{tabular}

(Fig. 10). However, by increasing the risk preference of the decision maker, the optimal solution leads to an NPV increase of a specific scenario. For example, with values of the risk tolerance $\rho=-0.01$ and $\rho=-0.008$, the optimal solution maximizes the NPV of Scenarios 3 and 4 because they are the most likely scenarios. If the decision maker becomes more risky $(\rho=-0.005)$ the optimal solution maximizes the NPV for the Scenario 2 (because it is more profitable, as can be seen in Table V), despite reducing the EV due to the lower profitability of the remaining scenarios. If the decision maker takes a highly risky attitude (in this case $\rho=-0.002$ ), the solution obtained coincides with that resulting from a deterministic approach considering only the Scenario 2. In conclusion, the decision maker takes risk with the possibility of increasing profitability in the event that the occurrence of Scenario 2 is higher than expected.

As shown, the proposed methods yield solutions that improve those obtained by the deterministic approach in the presence of risk. On the other hand, it is also possible to obtain solutions to the level of risk that the decision maker is willing to take. Moderate attitudes toward risk lead to configurations more insensitive to changes in wind direction; however, increasing the risk preference, the trend is to maximize the 
TABLE VII

RESUlts OF CASE 1: NPV (M€) BY VARYING THE RISK PREFERENCE

\begin{tabular}{|l|c|c|c|c|c|}
\hline & Scenario 1 & Scenario 2 & Scenario 3 & Scenario 4 & EV \\
\hline$\rho=0.005$ & 20.84 & 20.94 & 20.99 & 20.99 & 20.96 \\
\hline$\rho=0.1$ & 20.84 & 20.94 & 20.99 & 20.99 & 20.96 \\
\hline$\rho \rightarrow \pm \infty$ & 20.84 & 20.94 & 20.99 & 20.99 & 20.96 \\
\hline$\rho=-0.01$ & 20.49 & 20.85 & 21.03 & 21.03 & 20.95 \\
\hline$\rho=-0.008$ & 20.20 & 20.77 & 21.05 & 21.05 & 20.93 \\
\hline$\rho=-0.005$ & 20.81 & 21.17 & 20.53 & 17.26 & 20.16 \\
\hline$\rho=-0.002$ & 20.76 & 21.21 & 20.40 & 16.28 & 19.94 \\
\hline
\end{tabular}

TABLE VIII

WIND DIRECTIONS SCENARIOS

\begin{tabular}{|c|c|c|c|c|}
\hline Scenario (Probability) & $C(\mathrm{~m} / \mathrm{s})$ & \multicolumn{3}{|c|}{ Directions (Probability \%) } \\
\hline$S_{1}(2.25 \%)$ & 7.5 & ENE $(20 \%)$ & E $(70 \%)$ & ESE $(10 \%)$ \\
\hline$S_{2}(8.25 \%)$ & 6.5 & ENE $(20 \%)$ & $\mathrm{E}(70 \%)$ & ESE $(10 \%)$ \\
\hline$S_{3}(4.50 \%)$ & 5.5 & ENE $(20 \%)$ & E $(70 \%)$ & ESE $(10 \%)$ \\
\hline$S_{4}(9.75 \%)$ & 7.5 & NE $(20 \%)$ & ENE $(70 \%)$ & E $(10 \%)$ \\
\hline$S_{5}(35.75 \%)$ & 6.5 & NE $(20 \%)$ & ENE $(70 \%)$ & E $(10 \%)$ \\
\hline$S_{6}(19.50 \%)$ & 5.5 & NE $(20 \%)$ & ENE $(70 \%)$ & E $(10 \%)$ \\
\hline$S_{7}(3.00 \%)$ & 7.5 & E $(20 \%)$ & ESE $(70 \%)$ & SE $(10 \%)$ \\
\hline$S_{8}(11.00 \%)$ & 6.5 & E $(20 \%)$ & ESE $(70 \%)$ & SE $(10 \%)$ \\
\hline$S_{9}(6.00 \%)$ & 5.5 & E $(20 \%)$ & ESE $(70 \%)$ & SE $(10 \%)$ \\
\hline
\end{tabular}

TABLE IX

RESUlts of CASE 2: NPV (M€) BY VARYING THE RISK PREFERENCE

\begin{tabular}{|l|c|c|c|c|c|c|c|c|c|c|}
\hline & $S_{1}$ & $S_{2}$ & $S_{3}$ & $S_{4}$ & $S_{5}$ & $S_{6}$ & $S_{7}$ & $S_{8}$ & $S_{9}$ & EV \\
\hline$\rho=0.1$ & 34.81 & 21.10 & 7.45 & 34.81 & 21.10 & 7.45 & 34.81 & 21.10 & 7.45 & 19.06 \\
\hline$\rho \rightarrow \pm \infty$ & 34.81 & 21.10 & 7.45 & 34.81 & 21.10 & 7.45 & 34.81 & 21.10 & 7.45 & 19.06 \\
\hline$\rho=-0.1$ & 34.87 & 21.06 & 7.29 & 34.87 & 21.06 & 7.29 & 34.87 & 21.06 & 7.29 & 19.00 \\
\hline$\rho=-0.03$ & 34.26 & 20.56 & 6.94 & 35.00 & 21.21 & 7.43 & 29.02 & 16.02 & 3.49 & 18.07 \\
\hline
\end{tabular}

profitability of a given scenario without taking into account the loss of profitability for the remaining possible scenarios.

\section{B. Case 2: Wind Direction and Intensity Uncertainty}

Case 2 considers the same conditions described in Case 1 , but with different wind conditions, and adds uncertainty in the scale parameter of Weibull distribution. The scenarios considered in this case are shown in Table VIII.

The solution reached by the algorithm, taking into account the MEV criterion, is shown in Fig. 10. Table VI shows the most relevant economic performance of the solution obtained.

Table IX presents the results obtained with the MEU criterion, varying the risk preference of the decision maker. It can be seen that the solution obtained with neutral and aversive attitudes to risk $(\rho \geq 0)$ is the same as that obtained with the MEV criterion. Risk preference attitudes $(\rho<0)$ lead to an increase in the profitability for the Scenario 4. Scenarios 1 and 4 provide the highest NPV but the higher probability of Scenario 4 leads the algorithm to increase the profitability of such a scenario.

Fig. 12 shows the solutions obtained for the levels of risk preference $\rho=-0.1$ and $\rho=-0.03$, respectively. As can be seen, by increasing the risk preference of decision maker, the turbines selected change from WTB to WTA because this turbine can provide a bit more power despite requiring a slightly

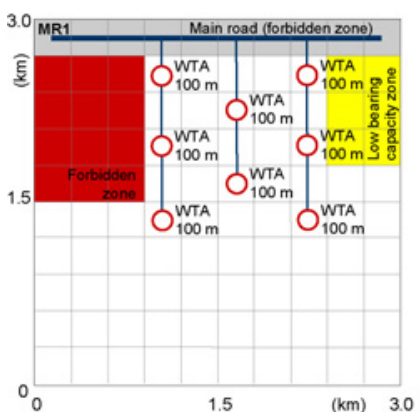

(a) (b)

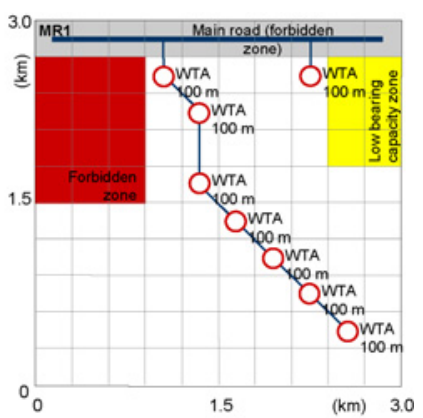

Fig. 12. Optimal layout obtained for Case 2 by the MEU by varying the risk tolerance of the decision maker. (a) $\rho=-0.1$. (b) $\rho=-0.03$.

higher initial investment. It can also be seen how by increasing the risk from $\rho=-0.1$ to $\rho=-0.03$, the geographical layout of the wind generator changes to maximize energy capture that would be produced for the Scenario 4 .

\section{CONCLUSION}

The design of a wind farm is an extremely complex task that involves a large number of variables. At the project stage, the behavior of many of these variables is difficult to characterize either due to factors, such as errors in the estimation of costs and uncertainty in economic behavior, or due to the random nature of some of the variables, such as the wind. Among all of the variables that influence the profitability of a wind farm project, the characteristics of the wind have the greatest influence on the plant configuration and its economic efficiency. Therefore, in this paper, the risk analysis and decision making has focused on the uncertainty in wind resource (direction and speed) characterization.

The performance of the proposed method has been successfully verified by analyzing a set of test cases, with different wind scenarios. As a result, when the risk analysis was included, the optimization process of the wind farm led to solutions (plant configurations) less sensitive to the uncertainty than the deterministic solution. In addition, the proposed methods allowed us to obtain configurations that met the level of risk that the developer wishes to assume. Furthermore, the algorithm provided information on the levels of profitability under uncertainty in the wind characterization.

\section{REFERENCES}

[1] World Wind Energy Association. (2011, Apr.). World Wind Energy Report 2010 [Online]. Available: http://www.wwindea.org

[2] P. R. Garvey, Analytical Methods for Risk Management: A Systems Engineering Perspective. New York: Taylor \& Francis, 2009.

[3] P. R. Garvey, System-of-Systems Risk Management: Perspectives on Emerging Process and Practice. Bedford, MA: MITRE Corporation, Jan. 2005.

[4] L. Jarass, L. Hoffmann, A. Jarass, and G. Obermair, Wind Energy. Berlin, Gremany: Springer-Verlag, 1981.

[5] I. Y. F. Lun and J. C. Lam, "A study of Weibull parameters using longterm wind observations," Renew. Energy, vol. 20, no. 2, pp. 145-153, Jun. 2000.

[6] G. Mosetti, C. Poloni, and B. Diviacco, "Optimization of wind turbine positioning in large wind farms by means of a genetic algorithm," $J$. Wind Eng. Ind. Aerodyn., vol. 51, no. 1, pp. 105-16, 1994. 
[7] U. Ozturk and B. Norman, "Heuristic methods for wind energy conversion system positioning," Elec. Power Syst. Res., vol. 70, no. 3, pp. 179-85, Aug. 2004.

[8] S. A. Grady, M. Y. Hussaini, and M. M. Abdullah, "Placement of wind turbines using genetic algorithms," Renew. Energy, vol. 30, no. 2, pp. 259-270, Feb. 2005.

[9] G. Marmidis, S. Lazarou, and E. Pyrgioti, "Optimal placement of wind turbines in a wind park using Monte Carlo simulation," Renew. Energy, vol. 33, no. 7, pp. 1455-1460, Jul. 2008.

[10] J. S. González, A. G. G. Rodríguez, J. C. Mora, J. R. Santos, and M. B. Payán, "Optimization of wind farm turbines layout using an evolutive algorithm," Renew. Energy, vol. 35, no. 8, pp. 1671-1681, Aug. 2010.

[11] J. S. González, A. G. G. Rodríguez, J. C. Mora, M. B. Payán, and J. R. Santos, "Overall design optimization of wind farms," Renew. Energy, vol. 36, no. 7, pp. 1973-1982, 2011.

[12] A. G. G. Rodríguez, J. S. González, J. R. Santos, M. B. Payán, and J. C. Mora, "Global optimization of wind farms using evolutive algotihms," in Wind Power Systems: Applications of Computational Intelligence. Berlin, Germany: Springer, 2010.

[13] C. Kongnam, S. Nuchprayoon, S. Premrudeepreechacharn, and S. Uatrongjit, "Decision analysis on generation capacity of a wind park," Renew. Sustain. Energy Rev., vol. 13, no. 8, pp. 2126-2133, 2009.

[14] R. Spillman, "Genetic algorithms, nature's way to search for the best," Dr. Dobb's J., vol. 8, no. 2, pp. 26-30, Feb. 1993.

[15] J. J. Grefenstette, "Optimization of control parameters for genetic algorithms," IEEE Trans. Syst. Man, Cybern., vol. 16, no. 1, pp. 122-128, Jan.-Feb. 1986.

[16] D. Goldberg, Genetic Algorithms in Search, Optimization and Learning. Reading, MA: Addison-Wesley, 1989.

[17] J. S. González, A. G. G. Rodríguez, J. C. Mora, J. R. Santos, and M. B. Payán, "A new tool for wind farm optimal design," in Proc. IEEE Bucharest PowerTech Conf., Jun.-Jul. 2009, pp. 1-7.

[18] J. C. Mora, "Optimización global de parques eólicos mediante algoritmos evolutivos," Ph.D. dissertation, Dept. Electric. Eng., Univ. Sevilla, Seville, Spain, Sep. 2008.

[19] J. R. Santos, M. B. Payán, J. Calero, and J. C. Mora, "An evolutive algorithm for wind farm optimal design," Neurocomputing, vol. 70, nos. 16-18, pp. 2651-2658, 2007.

[20] D. Luce and H. Rafia, Games and Decisions: Introduction and Critical Survey. New York: Wiley, 1957.

[21] M. Junginger, A. Faaij, and W. C. Turkenburg, "Cost reduction prospects for offshore wind farms," Wind Eng., vol. 28, no. 1, pp. 97-118, 2004.

[22] I. Katic, J. Højstrup, and N. O. Jensen, "A simple model for cluster efficiency," in Proc. EWEC, 1986, pp. 407-409.

[23] S. Frandsen, R. Barthelmie, S. Pryor, O. Rathmann, S. Larsen, J. Højstrup, and M. Thøgersen, "Analytical modelling of wind speed deficit in large offshore wind farms," Wind Energy, vol. 9, no. 1, pp. 39-53, Jan. 2006
[24] S. T. Frandsen, "Turbulence and turbulence-generated structural loading in wind turbine clusters," Ph.D. thesis dissertation, Wind Energy Dept., Ris $\varnothing$ Natl. Lab., Tech. Univ. Denmark, Copenhagen, Denmark, Risø-R1188(EN), 2007.

[25] W. Weibull, "A statistical distribution function of wide applicability," $J$. Appl. Mech.-Trans. ASME, vol. 18, no. 3, pp. 293-297, 1951.

[26] T. Burton, D. Sharpe, N. Jenkins, and E. Bossanyi, Wind Energy Handbook. New York: Wiley, 2001.

[27] R. Prim, "Shortest connection networks and some generalizations," Bell Syst. Tech. J., vol. 36, no. 6, pp. 1389-1401, 1957.

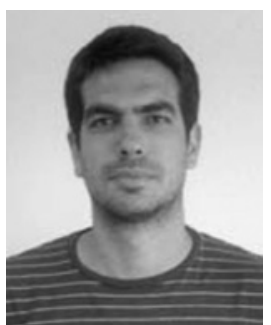

Javier Serrano González received the M.Sc. degree in electrical engineering from the University of Seville, Seville, Spain, in 2007. He is currently pursuing the $\mathrm{Ph} . \mathrm{D}$. degree in electrical engineering with the University of Seville.

His current research interest includes renewable energy.

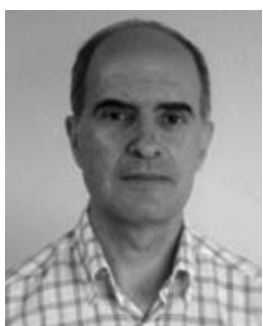

Manuel Burgos Payán received the Ph.D. degree in electrical engineering from the University of Seville, Seville, Spain, in 1994.

Since 1983, he has been with the Department of Electrical Engineering, School of Engineering, University of Seville, where he is currently an Associate Professor. His current research interests include electrical machines, renewable energy, and power quality.

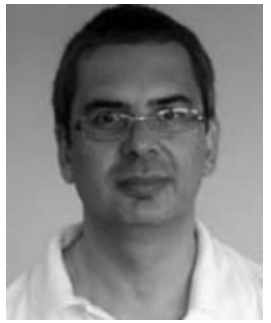

Jesús M. Riquelme-Santos received the Ph.D. degree in electrical engineering from the University of Seville, Seville, Spain, in 1999.

Since 1994, he has been with the Department of Electrical Engineering, School of Engineering, University of Seville, where he is currently a Professor. His current research interests include power optimization and control, power system analysis, and power quality. 